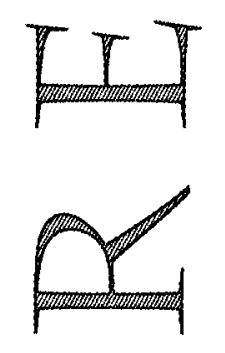

\title{
Adverse Drug Reaction Tracking and Management in an Integrated Health Care System
}

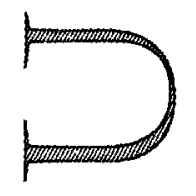

Adverse drug reactions cost the U.S. health care system more than $\$ 76$ billion annually. In 1996 alone, the U.S. Food and Drug Administration's Medwatch program screened more than 170,000 reports of adverse drug reactions. Despite these overwhelming numbers, however, experts agree that such reactions remain under reported, and accrediting bodies are concerned.
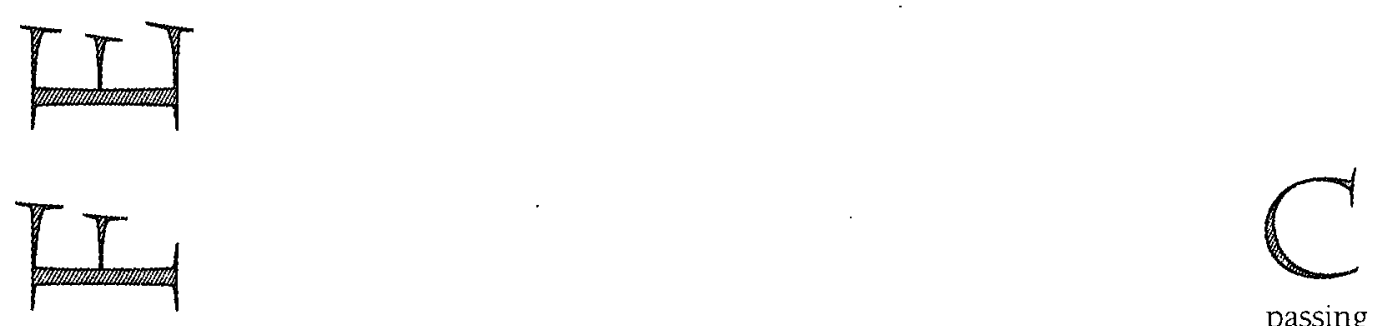

oncern about adverse drug reaction (ADR) reporting systems is neither new nor a passing trend. Medwatch Director Diane Kennedy reports that her organization takes every opportunity to make providers aware of the need to track ADRs, especially those that are particularly serious or unexpected.

Historically, the Joint Commission for Accreditation of Healthcare Organizations (JCAHO) was the key stimulus for ADR reporting in hospitals. Prior to 1992, JCAHO recommended ADR monitoring and reporting. That language was changed in 1992 to require ADR monitoring and reporting. However, with the new, more generic standards introduced by JCAHO in 1996, the language concerning ADRs is less clear and simply states that programs should monitor ADRs and comply with state and federal law. This leaves many practitioners wondering, "What laws?" There are no state or federal laws that speak directly to ADR monitoring and reporting. 
Table 1. Adverse Drug Reaction Review Methods

\begin{tabular}{|c|c|c|}
\hline Review Method & Benefits & Problems/Shortfalls \\
\hline \multirow[t]{3}{*}{ Voluntary Reporting to Manufacturer } & - Oldest established reporting system & Paperwork can be voluminous \\
\hline & $\begin{array}{l}\text { - Prescriber reports directly to manu- } \\
\text { facturer, who then reports to } \\
\text { MedWatch }\end{array}$ & $\begin{array}{l}\text { Reporting clinician must find telephone } \\
\text { numbers and/or contact information } \\
\text { for manufacturer }\end{array}$ \\
\hline & $\begin{array}{l}\text { - System is voluntary and no inhouse } \\
\text { forms or policies are needed }\end{array}$ & $\begin{array}{l}\text { Few reports are received unless reaction } \\
\text { is serious }\end{array}$ \\
\hline \multirow[t]{3}{*}{$\begin{array}{l}\text { Voluntary Provider Identification } \\
\text { (inhouse) }\end{array}$} & $\begin{array}{l}\text { - Existing staff reports ADRs when } \\
\text { identified }\end{array}$ & $\begin{array}{l}\text { Providers may perceive reporting to be } \\
\text { punitive or an indication of poor care }\end{array}$ \\
\hline & - Forms can be very simple & $\begin{array}{l}\text { The facility's definition of adverse drug } \\
\text { reaction may be too narrow or too broad }\end{array}$ \\
\hline & - Periodic inhouse review is possible & $\begin{array}{l}\text { The perception of additional paperwork } \\
\text { may dissuade providers from reporting }\end{array}$ \\
\hline \multirow[t]{3}{*}{ Alerting Order Method } & $\begin{array}{l}\text { - Trained pharmacy staff routinely screens } \\
\text { for those red flags that commonly indicate } \\
\text { an ADR }\end{array}$ & $\begin{array}{l}\text { The burden of screening falls on the } \\
\text { designated review staff, usually pharmacy }\end{array}$ \\
\hline & - Most serious ADRs are caught early & $\begin{array}{l}\text { Some adverse drug reactions will be missed } \\
\text { if there is no associated alerting order }\end{array}$ \\
\hline & - Frequent review identifies patterns early & $\begin{array}{l}\text { Some alerting orders will not result in } \\
\text { identification of an ADR; time will be spent } \\
\text { simply investigating }\end{array}$ \\
\hline
\end{tabular}

Nonetheless, astute clinical staff and risk managers in all health care settings must recognize that ADRs pose a threat, increase risk, and must be monitored in both hospital and ambulatory programs.

\section{ASSESSING, IMPROVING CARE AND PROCESSES}

The National Committee for Quality Assurance (NCQA) does not specifically address ADR monitoring in its accreditation standards. Instead, the organization stresses continuous assessment and improvement of care and processes. NCQA also encourages a quality improvement system centered on structure, outcome, and process.

A quality improvement process that provides adverse drug reaction monitoring begins with an effective means of tracking ADRs. Good tracking methods divide ADRs into several types which may include allergies (which account for $5 \%$ to $20 \%$ of all ADRs), drug interactions, or idiosyncratic reactions.
These methods also rate the reaction in terms of severity and look at predisposing factors such as age and gender, patient genetics or ethnicity, concurrent disease, polypharmacy, and the dosel frequency/route of the suspect medication. Finally, the best methods seek ways to educate and inform clinicians and patients about those ADRs that are preventable.

Unfortunately, few methods are completely successful in collecting, reviewing, and reporting $A D R s$, especially when issues as simple as preparing a workable definition for adverse drug reaction can be problematic. Some common methods used, as well as their pros and cons, are listed in Table 1. Following is an example of how one company has addressed ADRs.

\section{THE FALLON HEALTHCARE SYSTEM}

The Fallon Healthcare System is an integrated health care delivery system in
Worcester, Massachusetts, encompassing St. Vincent Hospital, a 363-bed acute care hospital; a group model managed care organization; and an insurance plan called Fallon Community Health Plan. Fallon's philosophy is that horizontal and vertical integration of information systems permits better patient care. Accordingly, its inpatient and outpatient pharmacies have separate databases that share information, and pharmacists have ready access to information stored in Fallon's medical system. With both inpatient and outpatient populations to consider, pharmacy clinical coordinators faced the unique challenge of establishing a system that would work for both areas and overcome the traditional hurdles of ADR reporting. Their goals-to decrease physician visits, auxiliary prescriptions, hospital admissions, and deaths related to ADRsfocused on improved quality of life for their patients. Fallon's pharmacy clinical coordinators developed an inpatient program that has made a significant 
impact in the five years it has been in existence. However, the two-year-old combined system that covers both inpatient and outpatient care has enhanced care delivery further.

Fallon selected an alerting order system for St. Vincent, the hospital portion. Simply put, this system requires monitoring by the pharmacy. Certain drugs are identified as frequently used in relation to ADRs. The list includes diphenhydramine, epinephrine, and protamine sulfate. In addition, abnormal lab results often sound an alarm that an ADR may have occurred. Fallon's integrated medical and pharmacy data was the essential element in the latter form of screening. Clinical pharmacists are automatically notified and can review all abnormal lab results. Of particular concern are those findings related to drugs with narrow therapeutic windows, electrolyte imbalances, or clotting factors. Last, hospital admissions are routinely reviewed by diagnosis to determine if they were related to an ADR. These screening methods were successfully implemented at the hospital, and a database was created. However, the low number of ADRs reported led the clinical management team to believe that under reporting continued to be a problem. To increase reporting, the team implemented a voluntary provider identification program.

In Fallon's outpatient facilities, the alerting order system was more difficult: to apply uniformly. Medications are prescribed in different ways in the ambulatory selling, and monitoring is more difficult. Patients present prescriptions for diphenhydramine or steroid creams for a host of reasons, and screening can be cumbersome. Also, in ambulatory settings, the patient or patient's family members are usually the first to identify an ADR, and they may or may not report the occurrence to the prescriber. Finally, the hospital lends structure to ADR reporting because the number of patients is limited, and because the patient's medical record is all inclusive and conveniently located on the unit. In the ambulatory setting, the sheer volume of clients and prescriptions complicates screening, and the medical record is often not accessible to immediate review at the time the prescription is filled. After weighing several options, Fallon's chose a voluntary provider identification program to identify ADRs in its outpatient population.

The combined use of the alerting order and voluntary provider identification systems in the Fallon system increased opportunities to identify ADRs. In every step of the health care continuum, including outpatient service, emergency room treatment, and hospitalization, screening mechanisms are in place.

\section{THE PROS AND CONS OF VOLUNTARY IDENTIFICATION}

While Fallon is a success story, the implementation of any system to detect ADRs must be done carefully and moni-

Figure 1. Drug Reaction Notification Form

\section{The Fallon Clinic DRUG REACTION NOTIFICATION FORM}

Patient's Name

$\mathrm{MR \#}$

SUSPECTED ADVERSE DRUG REACTION

Definition of adverse drug reaction and instructions are found on the back of this card.

Date / /

Suspected Drug

Description of Reaction

Submitted by R.N. / M.D.

COMPLETE AND RETURN TO THE PHARMACY CLINICAL COORDINATOR

FORM \#19848 (REV, 4/96) POD 
The second key point of Fallon's system is simplicity. Fallon uses a bright pink, preaddressed post card (see Figure 1) that is readily available throughout the system, eye-catching, and very easy to complete. The system's nonpunitive, information-gathering purpose also is stressed in every available communication medium.

In this system, the term "provider" refers to any health care providernurse, pharmacist, physician extender, physician, or mid-wife. This multidisciplinary approach increases the pool of potential ADR reporters and provides a wide base for screening.

\section{TRACKING FINDINGS}

Leslie Fish, Pharm.D., and Laurie Fromm, Pharm.D., serve as outpatient and inpatient clinical coordinators, respectively, for the Fallon Healthcare System. They review every possible ADR reported and complete an adverse effect report. Their findings are tracked on separate database systems, but Fish and Fromm regularly discuss, compare, and contrast findings to identify issues of mutual concern.

While Fish believes that reporting could be better in the outpatient setting, she is pleased that providers report as many ADRs as they do. Using the integrated database, Fallon's clinical coordinators have identified trends and taken actions to alert and educate prescribers and prevent further adverse events (see Table 2). Three examples of the system in action demonstrate its effectiveness.

\section{Fentanyl Patch}

Pharmacists noted that the fentanyl patch, designed for use in treating chronic pain in those patients who are unable to take medication orally, was being used inappropriately in both the inpatient and outpatient settings. Their concerns were based on increased use of the patch without regard to its unique dosing schedule, increased cost, and concurrent reporting of ADRs. The pharmacists' response was two-foldthey developed appropriate prescribing guidelines with consultation from pain management specialists and they conducted a retrospective drug-use evaluation (DUE) of the patch. The DUE revealed several problems, although they differed in hospitalized and ambulatory patients. In inpatients, there was a tendency to prescribe fentanyl patches for acute pain. In outpatients, the patch often was prescribed for patients who were able to take oral drugs.

In both populations, but especially in inpatient populations, documentation of underlying disease state and target symptoms was less than optimal, and initial doses and dosing intervals often were too high and too long, respectively. Educational information and prescribing guidelines were communicated uniformly. Prescribing rates for the fentanyl patch have not declined since this review was done in September and October of 1996; however, informal review indicates that patient selection is more appropriate, and prescriber documentation has improved. A follow-up evaluation is scheduled for this fall.

\section{Hyperkalemia}

When Fromm's data indicated an increase in admission diagnoses labeled hyperkalemia, the clinical team took action again. Their hypothesis, which they eventually found to be wrong, was that agents such as the potassiumsparing diuretics were at fault. However, careful review of outpatient records revealed an unanticipated culprit: ACE inhibitors. These agents can elevate potassium, particularly in those patients with chronic renal failure, diabetes, or electrolyte disturbances. Once again, educational information was widely distributed.

During periodic review, Fish and Fromm also noted that while hospitalizations secondary to hyperkalemia decreased initially, they started to climb
Table 2. Actions Taken Pursuant to ADR Trend Identification

Major educational campaigns to all
clinicians

Emphasis on patient education

Publication of clinical advisories to prescribers

"Dear Doctor" letter that identifies specific patients with contact information

Distribution of laminated dosing cards

Newsletter articles which include history, problem, guidelines, and description of high risk patients

Periodic reassessment and reminder if necessary

again. A second educational campaign was initiated, this time enhanced by a "Dear Doctor" letter that identified potentially-affected patients, reminded prescribers about factors that predispose patients to hyperkalemia, and included the patient's phone number to facilitate contact. It is still too soon to know if the incidence of hyperkalemia secondary to ACE inhibitor use has declined, but Fish reports that many health care providers contacted the clinical coordinators to acknowledge receipt of the "Dear Doctor" letter, and further, to express appreciation and pledge immediate action. Follow-up studies will be conducted next year.

\section{Digoxin}

Review of data from inpatient and outpatient settings noted a trend of admissions secondary to digoxin toxicity. A six-step process promoted in Fallon's newsletter targeted lower serum concentrations, careful monitoring when renal function is compromised, heightened awareness of drug interactions and patient education, and appropriate timing for blood samples as steps to reduce ADRs relating to digoxin. The process also explained the reasons for increased digoxin use and what problems it was

Continued on page 650 